\title{
Proposal for a Control System to Optimize Water use in Households in Peru
}

\author{
Witman Alvarado-Diaz*, Brian Meneses-Claudio, Avid Roman-Gonzalez \\ Universidad de Ciencias y Humanidades (UCH), Image Processing Research Laboratory (INTI-Lab), Lima, Peru
}

\begin{tabular}{l} 
A R T I C L E I N F O \\
\hline Article history: \\
Received: 17 April, 2020 \\
Accepted: 25 July, 2020 \\
Online: 17 September, 2020 \\
\hline Keywords: \\
Water saving \\
Control \\
Water waste \\
Solenoid valves \\
Domestic shower \\
Environmental impact \\
\hline
\end{tabular}

\begin{abstract}
A B S T R A C T
Water is an important vital resource, and must be protected and saved. Unfortunately, millions of liters of water are wasted annually at the national level in Peru, one of the factors is the discomfort when people take a hot shower, because first the water is cold, which is contained in the pipes of domestic connections with the heating tank, the cold water is wasted by sending directly to the drain until the water to be in a pleasant temperature, that means about 5 liters of water are wasted. The technology within engineering has carried out a variety of innovations that respond and solve problems related to water saving, that's why, this paper proposes to create an automated system that saves the wasted water in domestic showers, the proposal is characterized by being sustainable, for its environmental and economic impact; solving in this way a latent problem of society as well as raising public awareness of the benefits of saving water. As a result, a preliminary prototype was obtained, which demonstrates the basic operation of the proposed system.
\end{abstract}

\section{Introduction}

The main problem focus in this work is the waste of water, which, according to the Autoridad Nacional Del Agua (ANA) in Peru, approximately $37 \%$ is wasted and $50 \%$ is wasted in urban areas, in addition to coastal areas only $17 \%$ of the water is used. The proposed technology will promote greater awareness of water conservation practices, thus helping to reduce drinking water consumption in homes.

In [1], a tank is built that saves the hot water for aquariums of fish, this water is collected from power plants, which normally throw the water into the sea causing thermal pollution. The main purpose of the project is to recycle the waste of hot water produced by the power plants, taking advantage of it for agriculture; in this way, it is possible to maintain the thermal equilibrium of the aquariums with fish.

In [2], they mention that in a common domestic water supply, the connection of water pipes with the water heater is usually long, whereby the water is trapped, which is at an uncomfortable temperature, so users waste this water by letting it flow down the drain until water has a pleasant temperature. It proposed to save the trapped water, allows the circulation of hot and cold water by introducing a new component called back box installed inside the domestic water supply, this allows the water to flow in the

\footnotetext{
*Corresponding Author: Witman Alvarado-Diaz, Email: walvarado@uch.edu.pe
}

opposite direction to the pressure of the line, the simulation showed the viability and effectiveness of the new approach.

In [3], they show us that magnetic induction water heater is a new device that can be used to heat the shower water, making a saving of water and energy; this heater consumes less electricity and does not store hot water; they mention that the induction heater is a device that aims to solve environmental and energy problems.

In [4], they mention that water consumption is increasing as the population grows, and it is the hotels that contribute significantly to the consumption of water, even more those that do not monitor the use of water, which results in millions of liters of wasted water per year, so the paper of the reference has a low-cost, precise, small and low-power wireless device for monitoring water in hotel showers.

In [5], the main references regarding the management of water demand are reviewed, as a strategy for efficient use in urban aqueducts; in addition, a management process is generated from the housing level to higher levels; some measuring equipment and low consumption devices are described; finally, the social mechanisms for efficient water use are listed.

Section 2 presents the development of the water saving system, recognizing the current domestic connections and the proposals in 
addition to the electronic control system. Section 3 contains the preliminary results obtained from the application of the preliminary water saving system. In section 4 , the reader can find the respective discussions and in section 5 the conclusions for the present paper.

\section{Methodology}

First, it must know the scheme of standard domestic supply, in homes that have a hot water tank, which distributes it throughout the house. In Figure 1, the reader can see a basic diagram of connections corresponding to a tank and a shower, which has a system of keys, those allows to control and mix the water to obtain different temperatures and quantities.

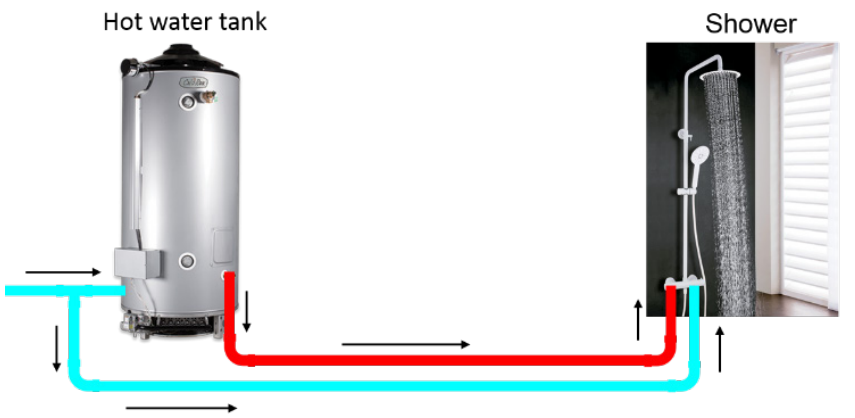

Figure 1: Diagram of the common connection of hot and cold-water pipes.

The aforementioned connections, it considers them to be inefficient, since to obtain a pleasant temperature, the cold water must be wasted until a pleasant temperature is obtained, which implies a huge waste of water, for which a new connection system is proposed, in addition of an electronic control system that saves water.

\subsection{Connection Design}

In order to save the cold water that accumulates in the hot water pipe, it is proposed to make the connections shown in Figure 2 , where the reader can observe, following the flow of water that when opening the hot water key, all the cold water of the pipe enters to the connections using the activation of the " $\mathrm{C}$ " solenoid valve, this cold water enters a water container until the temperature sensor detects that the water is hot, at that moment, the solenoid valve closes "C" and solenoid valve "B" is activated allowing water to flow into the shower; the cold water contained in the container will periodically come out with the activation of the solenoid valve "A" and the pump, making the hot water mix with the cold water contained; people can control the temperature of the water by opening the cold water; at the end, when the hot and cold water keys are closed, the system will be deactivated, closing all the solenoid valves; in the event that only the cold water key is opened, the system must act normally until the container is filled, then an alarm will be activated and the solenoid valve "B" will be activated and the solenoid valve "C" deactivated, allowing cold water to flow the shower in addition to the process to get the container empty.

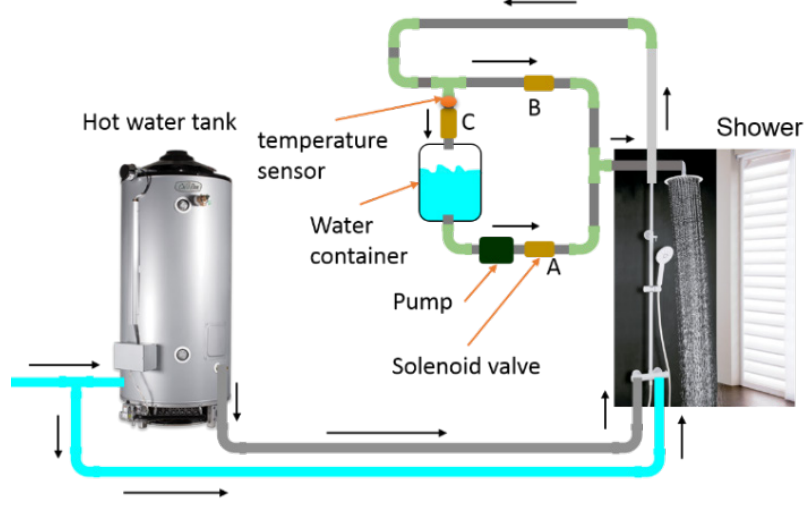

Figure 2: Proposal of connections for water saving.

\subsection{Electronic Control}

To carry out all the control of the aforementioned processes, an electronic test control system based on an Arduino nano is implemented, which is responsible for controlling relays, which can activate or deactivate the solenoid valves and the pump; for protection, the relays are connected a diode, a transistor and a resistor, as the reader can see in Figure 3.

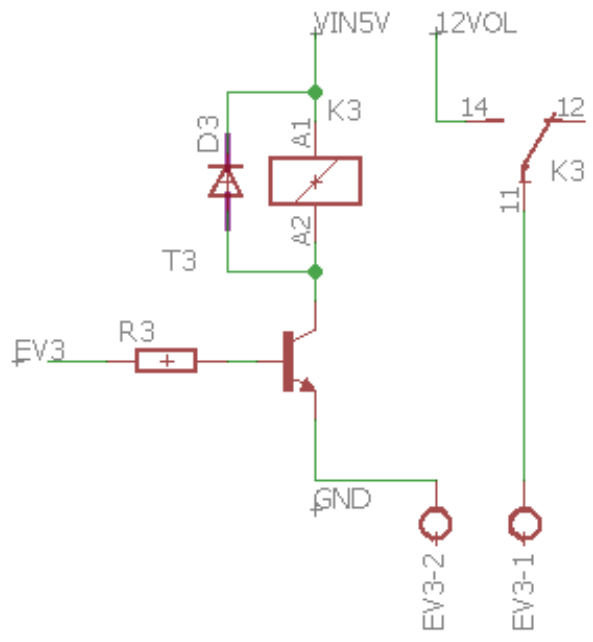

Figure 3: Relay connections.

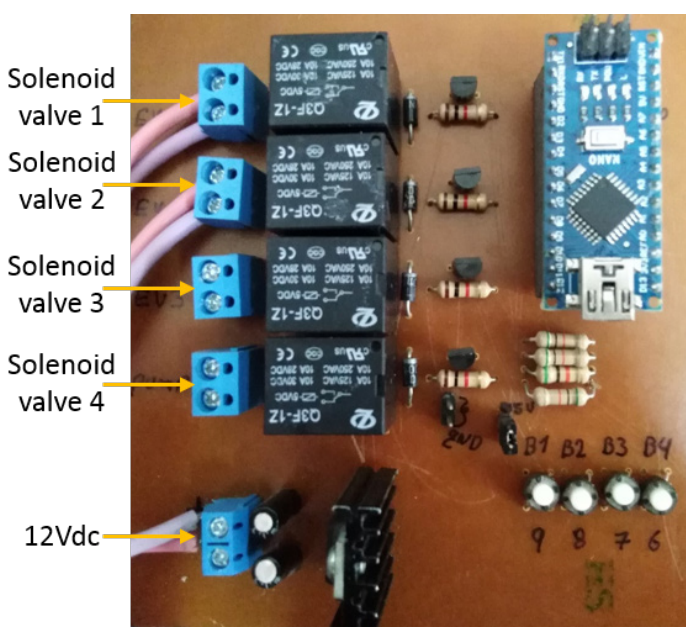

Figure 4: Electronic control board. 
In figure 4 , it can see the design of the control board, in which it can see the aforementioned relay, it can also see the connections of the Arduino nano, and its respective power supply also placed 4 buttons in order to make tests to the system, it is worth mentioning that the system designed is a preliminary system which tests are carried out to obtain a complete system in the future.

In Figure 5, it can see the basic programming scheme for the Arduino nano, in order to achieve the basic control of all components, and thus demonstrate its operation; as it can see with few instructions, it can make the system works in the same way as it was proposed at the beginning.

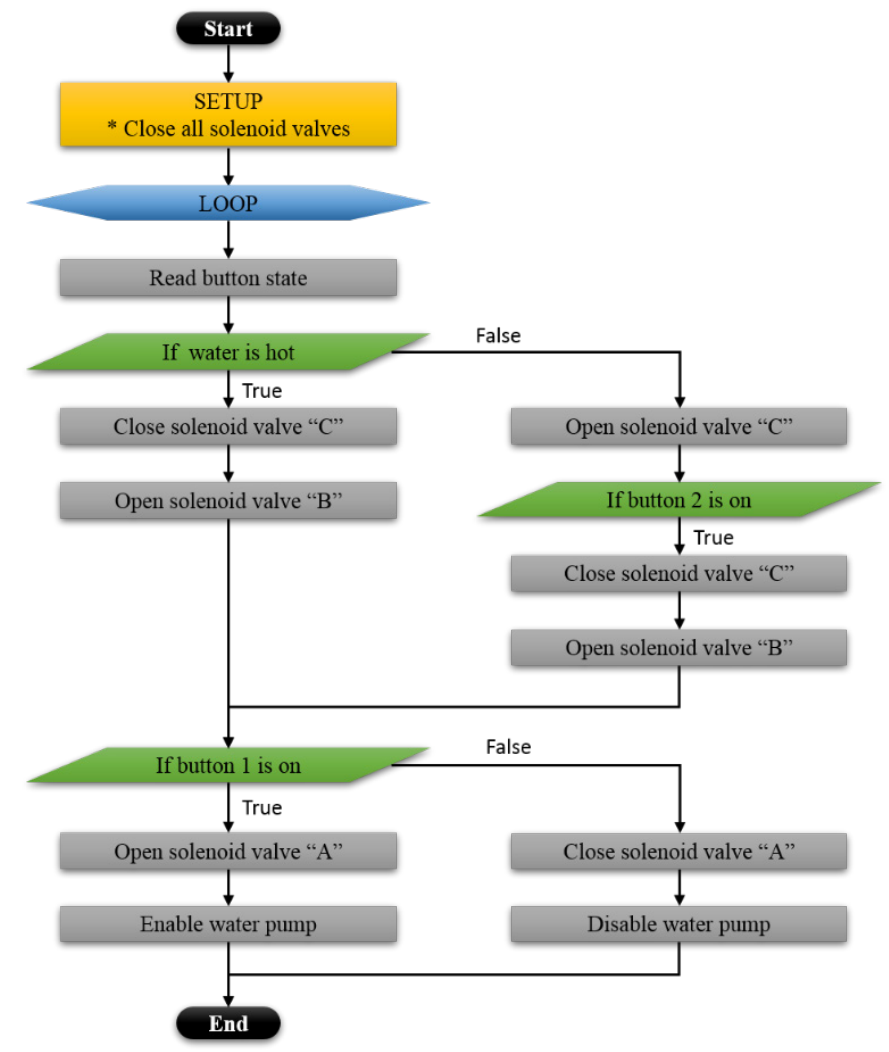

Figure 5: Programming diagram.

\section{Results}

As preliminary results, a model was built (Figure 6), in which the operation of the proposed system is demonstrated, this prototype has a similar operation, as proposed in the present investigation

Be aware that there are millions of people without access to drinking water and that its excessive use contributes to scarcity, water is a gift of nature that we must protect and share.

Around the world, there are commercial solutions that save water, however, none have alternative connections that divert water to a container, which saves it and spends it according to user requirements; the proposed system has this connection, to which add a control system, which together save water.

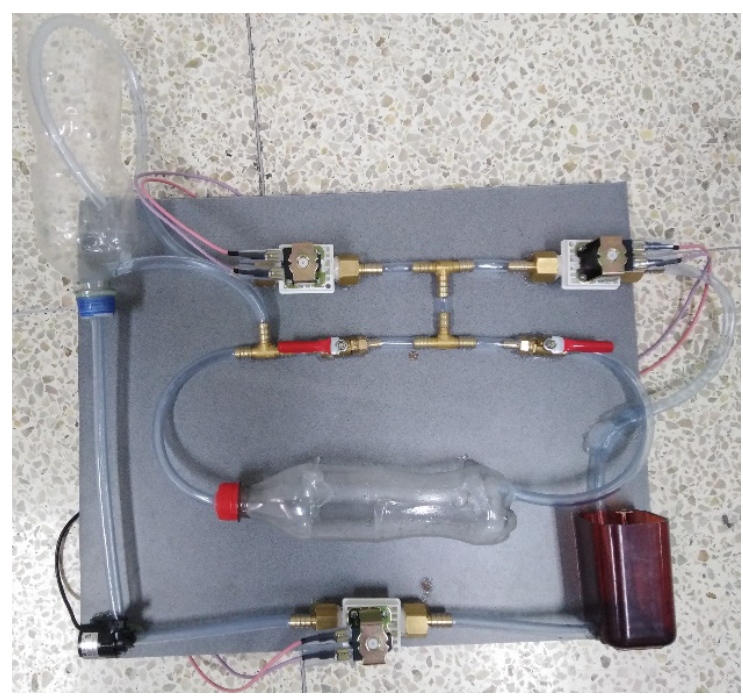

Figure 6: Test prototype.

Using the proposed system, it is possible to save in a family of 4 members, until 600 liters of water per month, which affects indirectly, reducing the amount to be paid for home water service. The 600 liters per month per family is calculated taking some minimum requirements, so the calculation of a single hot shower is performed, if it projects the calculation in a very long time, a very large saving of such a precious resource could be calculated.

Performing the respective calculations for the city of Lima, which has, according to the Instituto Nacional de Estadistica e Informatica del Perú (INEI), a total of 9 million 320 thousand inhabitants, considering only a saving of 4 liters per person, it could save approximately more than 37 million liters in just 1 day in Lima, therefore, monthly would mean a saving of more than approximately 1 billion liters of drinking water in the city of Lima.

\section{Discussions}

This project helps meet the sustainable development goals set by the United Nations (UN), explicitly helps with $6^{\text {th }}$ and $12^{\text {th }}$ Goal, which according to the UN in 2019 that 3 of 10 people do not have access to drinking water. In addition, it is mentioned that women and girls are responsible for collecting $80 \%$ of water in homes without access to water, which is a serious problem even more since being minors, they are exposed to various dangers. $40 \%$ of the world's population survive with water scarcity. An important fact to know is that less than $3 \%$ of the world's water is suitable for human consumption, of which $2.5 \%$ is frozen. Therefore, humanity has only $0.5 \%$ to cover all its needs. We must

Thanks to projects like ours, it is possible to save large amounts of water, as previously mentioned, this water would greatly benefit the poorest sectors of the city, since they are the ones who suffer from a worrying water shortage.

The test prototype has been simulated in the Proteus software (figure 7), in which it can demonstrate the correct operation of the prototype, thus evidencing that it is possible to build a system capable of allowing to save all the cold water that is normally 
wasted, before taking a shower. In the future, it is planned to build a robust and complex system that allows to save as much water as possible.
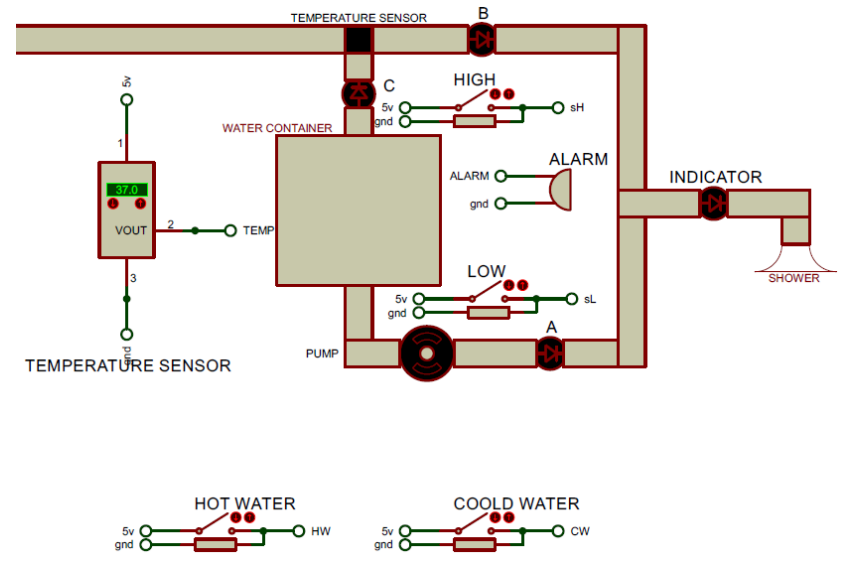

Figure 7: Simulation of the system

\section{Conclusion}

The designed control system contributes to the preservation of the environment and water saving by becoming a reliable device, contributing to the preservation of such a precious and limited resource. Using this type of projects, it will be able to achieve that the water reaches the neediest people and especially to the children of the whole world, since according to the UN, one of every four educational centers of primary level lacks water suitable for human consumption worldwide. In addition, another of the vulnerable populations are people living in rural areas, of which $80 \%$ use unsafe and unhealthy water sources. Finally, it is important to mention that approximately two thirds of the world's population $(4,000$ million people) suffer from severe water scarcity at least one month a year.
The present paper is an advance to a greater development of a system capable of optimizing the use of water in the homes of Lima Peru, a first advance is presented demonstrating that the project works and is applicable to save water in the showers of the houses that have a water heater tank, as well as in the hotel industry. The presentation of a prototype that simulates the functions that the final project could have is considered as a first step, in addition to the tests carried out in a circuit simulation, as a future vision, the development of an advanced electronic control system is proposed in order to save the maximum possible amount of water, in this way we contribute, so more people could have this important resource.

An important limitation that must be covered is security, since it is not raised in this research work, a security system must be developed to avoid possible current outflows that may affect users, in addition a control system must be added for the water flow, so that users can control it according to their preferences.

\section{References}

[1] A. Angani, K.B. Jun, Y.R. Musunuri, M. Akbar, K.J. Shin, "Development of Heat Storage and Delivery System Using Wasted Hot Water," in 2017 International Conference on Applied System Innovation (ICASI), 432-435, 2017, doi:10.1109/ICASI.2017.7988445.

[2] Y. Osais, M. Siddiqui, "A New Technique for Saving Water Trapped Inside Home Water Networks," in 2017 Intelligent Systems Conference (IntelliSys), 160-165, 2017, doi:10.1109/IntelliSys.2017.8324284.

[3] O.F. Rafael, M.C. Roberto, "Water heater by magnetic induction," in CONIELECOMP 2013, 23rd International Conference on Electronics, Communications and Computing, 192-197, 2013, doi:10.1109/CONIELECOMP.2013.6525784.

[4] P.J. Hawrylak, W. Nichols, X. Li, T. Johannes, R. Decook, K. Mongold, C. Cornell, L.A. Flint, A. Singh, "HydroSense: A Self-Powered Wireless Device for Monitoring Water Usage in Hotel Showers," in 2015 IEEE Global Humanitarian Technology Conference (GHTC), 2015 doi:10.1109/GHTC.2015.7343990.

[5] D. Gildardo, M. Silva, J.G. Erazo, "Eficiencia en el consumo de agua de uso residencial," Revista Ingenierías Universidad de Medellín, 11(21), 23-38, 2012. 